\title{
Annual variation in long-distance dispersal driven by breeding and non-breeding season climatic conditions in a migratory bird
}

\author{
Clark S. Rushing, Michele R. Dudash, Colin E. Studds and Peter P. Marra \\ C. S. Rushing (crushing@umd.edu) and M. R. Dudash, Graduate Program in Behavior, Ecology, Evolution, and Systematics, Univ. of Maryland, \\ College Park, MD, USA. - C. E. Studds, P. P. Marra and CSR, Migratory Bird Center, Smithsonian Conservation Biology Inst., National \\ Zoological Park, Washington DC, USA. CES also at: Dept of Geography and Environmental Systems, Univ. of Maryland, Baltimore County, \\ Baltimore, MD, USA.
}

\begin{abstract}
Long-distance dispersal is a fundamental process in ecology and evolution but the factors that influence these movements remain poorly understood in most species. We used stable hydrogen isotopes to quantify the rate and direction of longdistance immigration in a breeding population of American redstarts and to test whether the settlement decisions that result in long-distance dispersal are driven by habitat saturation or by the phenology of breeding-season resources. Our results provide evidence that both natal dispersal and breeding dispersal were influenced by the timing of breeding-season phenology, with both age classes more likely to disperse north in years when the onset of breeding-season phenology occurs earlier than normal. Yearlings were also more likely to disperse north following winters with poor habitat quality on their non-breeding grounds, demonstrating that carry-over effects from the non-breeding season influence natal dispersal in this species. Collectively, these results are consistent with the hypothesis that American redstarts use the phenology of breeding season resources as a cue to select breeding sites. Our results suggest that long-distance dispersal may allow individuals to rapidly respond to advancing phenology caused by global climate change, though their ability to do so may be constrained by long-term decline in habitat quality predicted for their tropical non-breeding grounds.
\end{abstract}

Dispersal, defined as the movement of an individual from its natal site to its first breeding site (i.e. natal dispersal) or between breeding sites used in successive years (i.e. breeding dispersal), is a phenomenon common to virtually all species (Clobert et al. 2012). In the majority of species, most individuals disperse over relatively small distances but a small proportion of individuals often disperse far beyond the mean or median dispersal distance, a phenomenon termed longdistance dispersal (Nathan et al. 2003). Despite the relative rarity of long-distance dispersal, empirical and theoretical studies have demonstrated that many ecological and evolutionary processes, including local adaption and speciation (Green and Figuerola 2005, Savolainen et al. 2007), population dynamics (Baguette 2003, Bohrer et al. 2005), range expansion (Kot et al. 1996), and the response of species to climate change (Higgins and Richardson 1999), are sensitive to the rate and magnitude of these events. Unfortunately, the inherent difficulty of tracking long-distance dispersal has limited progress on understanding the factors that drive these movements in most species (Clobert et al. 2012).

Understanding the factors that influence long-distance dispersal is especially difficult in small, highly mobile species due to the challenges of tracking individuals as they move over large distances (Nathan et al. 2003, Winkler 2005). Furthermore, there is growing evidence from both migratory and non-migratory species that many life history events, including long-distance dispersal, are shaped by the interaction of events across the annual cycle (Harrison et al. 2011). These seasonal interactions complicate the study of longdistance dispersal because decisions about where to breed may be determined partly by the conditions or events experienced earlier in the year and, for migratory species, at locations separated by thousands of kilometers. Unfortunately, most research on the causes of long-distance dispersal has focused exclusively on the role of events or conditions experienced during the breeding period. As a result, the lack of information about how non-breeding season events influence long-distance dispersal represents a major impediment to developing a mechanistic understanding of long-distance dispersal in both migratory and non-migratory species.

At present, only one study has provided direct evidence that events experienced during the non-breeding season influence long-distance dispersal. American redstarts Setophaga ruticilla are long-distance migratory birds that spend the temperate summer breeding throughout North America and migrate to the Caribbean and Latin America for the winter (Sherry and Holmes 1997). Working on a non-breeding population of redstarts in Jamaica, Studds et al. (2008) used stable hydrogen isotopes to show that individuals that occupied high-quality territories during their first winter departed earlier on spring migration and on average bred south of their natal latitude. In contrast, individuals 
from low-quality non-breeding territories departed later and dispersed north of their natal latitude. These results provide compelling evidence that habitat quality experienced during the non-breeding period is a primary driver of long-distance natal dispersal in this species, though the mechanisms behind this seasonal interaction remain poorly understood.

Two hypotheses were proposed to explain why later migrating individuals were more likely to disperse north of their natal site than individuals that migrated earlier (Studds et al. 2008). Under the 'saturation' hypothesis, individuals select breeding sites based on the availability of suitable habitat. Under this scenario, southern breeding sites become saturated by early migrating individuals, forcing later individuals to migrate to more northerly latitudes to locate unoccupied breeding habitat. Alternatively, individuals may use phenological cues to select breeding sites as a mechanism to ensure that reproductive activities coincide with peaks in resource abundance. Under this 'phenology' hypothesis, early migrating individuals will experience suitable breeding conditions and choose to settle at more southerly latitudes whereas later migrating individuals must continue migrating north to keep pace with the northward advance of resource phenology. Because the results of Studds et al. (2008) are consistent with both hypotheses, further testing is required to disentangle the mechanisms driving long-distance dispersal patterns in American redstarts.

In this study, we used stable hydrogen isotopes to quantify patterns of long-distance immigration in a breeding population of American redstarts and to test whether long-distance dispersal in this species is driven by habitat saturation or breeding-resource phenology. If the 'saturation' hypothesis is correct, we predicted 1) that individuals that held territories in high quality non-breeding habitat the preceding winter would be more likely to disperse south of their natal grounds whereas individuals from low-quality territories would be more likely to disperse north. Furthermore, these patterns should hold regardless of the timing of breeding-resource phenology. In contrast, if the 'phenology' hypothesis is correct, we predicted 2) that northward dispersal of redstarts should increase in years when the onset of breeding-season phenology occurs relatively early and should decrease in years when breeding-season phenology occurs relatively late.

Previous work on non-breeding redstarts has also demonstrated that rainfall patterns in the Caribbean can lead to annual variation in non-breeding habitat quality that exceeds variation caused by habitat type (Studds and Marra 2007), which in turn can drive annual differences in the timing of spring migration (McKellar et al. 2013). Because these large-scale habitat conditions should influence the migration phenology of all individuals in the same way, annual variation in non-breeding habitat quality is not predicted to influence patterns of long-distance dispersal under the 'saturation' hypothesis. Therefore, if the phenology hypothesis is correct, we further predicted 3) that northward dispersal should increase following winters with poor conditions across the Caribbean and decrease following winters with good conditions. Given the relative rarity of studies linking long-distance dispersal to environmental conditions, our analysis provides important mechanistic insights into the factors that influence long-distance dispersal and underscores the importance of considering how factors experienced across the full annual cycle influence these movements.

\section{Methods}

From 2009-2012, we studied a breeding population of American redstarts at the Patuxent Research Refuge in Laurel, Maryland, USA $\left(39^{\circ} 04^{\prime} \mathrm{N}, 76^{\circ} 47^{\prime} \mathrm{W}\right)$. Starting on 10 April of each year, the site was surveyed every three days from 06:00 to 12:00 along transects spaced $100 \mathrm{~m}$ apart to record any male seen or heard. During each survey, the territory boundaries of all males were mapped by following the individual for $10 \mathrm{~min}$ or until visual contact was lost and recording their approximate locations on a gridded map of the study site. The arrival date of each male was recorded as the first day in the 3-d survey period it was recorded. Males were captured in mist nets within 7-10 d of arrival using playback of conspecific song and a decoy. To ensure that individuals passing through on spring migration were not included in our analysis, only males that were confirmed on the same territory for $>1$ week were considered as part of the population. Female redstarts are cryptic during the nest building period and do not generally respond to conspecific playback. Therefore females were captured in mist nets while feeding fledglings later in the season.

Upon capture, individuals were classified as either yearlings ( $1 \mathrm{yr}$ old) or adults ( $>1 \mathrm{yr}$ old ) following Pyle et al. (1997), fitted with an aluminum US Fish and Wildlife Service leg band and a unique combination of plastic color bands, weighed to the nearest $0.1 \mathrm{~g}$, measured for body size (tarsus length and unflattened wing chord) to the nearest $0.5 \mathrm{~mm}$, and released. In addition, one tail feather (R3) and the distal $0.3 \mathrm{~mm}$ of each middle claw were sampled from each bird for stable hydrogen and stable carbon isotope analyses, respectively (see Supplementary material Appendix 1 for further details about isotope analysis).

\section{Determining dispersal status}

We used stable hydrogen isotope values from feather samples $\left(\delta^{2} \mathrm{H}_{f}\right)$ to probabilistically determine the origin of all individuals breeding in our study population. This method relies on the latitudinal gradient of abundance of hydrogen isotopes in North American precipitation and the fact that this isotopic gradient is incorporated into bird feathers (Hobson et al. 2012). Because redstarts grow their feathers on their breeding or natal grounds prior to fall migration (Pyle et al. 1997), the stable hydrogen isotope abundance in feathers of birds sampled during one breeding season reflects the geographic origin of these individuals from the previous year, providing a spatially unbiased estimate of long-distance dispersal (van Wilgenburg et al. 2012).

To determine the origin of all unknown-origin individuals in our population, we first estimated the annual local $\delta^{2} \mathrm{H}_{f}$ signatures for the study site. Because we did not have a marked population of individuals in 2009, we estimated the local signature as the mean $\delta^{2} \mathrm{H}_{f}$ value from breeding adult males $(n=44)$. Across the four years of the study, slightly 
over half of all banded adult males (57\%) were recaptured or resighted in subsequent years, similar to rates reported in other studies on American redstarts (Lemon et al. 1996). Therefore, the mean $\delta^{2} \mathrm{H}_{f}$ value from unbanded adult males in 2009 should provide a reasonable estimate of the local year-specific $\delta^{2} \mathrm{H}_{f}$ signature. In subsequent years, we used the mean $\delta 2 \mathrm{H}_{f}$ value of adults known to have bred at the study site the previous year $(2010: \mathrm{n}=10 ; 2011: \mathrm{n}=11 ; 2012$ : $\mathrm{n}=15)$. The use of year-specific $\delta^{2} \mathrm{H}$ signatures allowed us to explicitly account for annual differences in the local $\delta^{2} \mathrm{H}$ signature (Haché et al. 2012). Next, we centered the $\delta^{2} \mathrm{H}_{f}$ values from all recaptured individuals from 2010-2012 on the year-specific means and, because the mean-centered values were normally distributed (Shaprio-Wilk test: $W=$ $0.972, p=0.5123$ ), we used the standard deviation of these values $\left(7.18 \%\right.$ ) as a measure of local variation in $\delta^{2} \mathrm{H}_{f}$ values (Fig. 1).
Finally, we used the year-specific means and pooled standard deviation to probabilistically assign all unbanded individuals into one of three dispersal categories based on a predefined odds ratio for correctly classifying individuals as local. This odds ratio was used to calculate the range of $\delta^{2} \mathrm{H}_{f}$ values capturing a given area under each year-specific local distribution (e.g. 80\%). Individuals with $\delta^{2} \mathrm{H}_{f}$ values within this range were classified as local while individuals with $\delta^{2} \mathrm{H}_{f}$ values more negative or positive than the threshold range were classified as originating to the north or south, respectively (Fig. 1). Previous studies using hydrogen isotopes to determine the origin of songbirds have applied a correction factor to hydrogen values from yearling individuals to account for possible age-specific isotope discrimination (Haché et al. 2012, Studds et al. 2012). Over the course of our study, we recaptured six yearlings that were originally banded at our study site as nestlings and
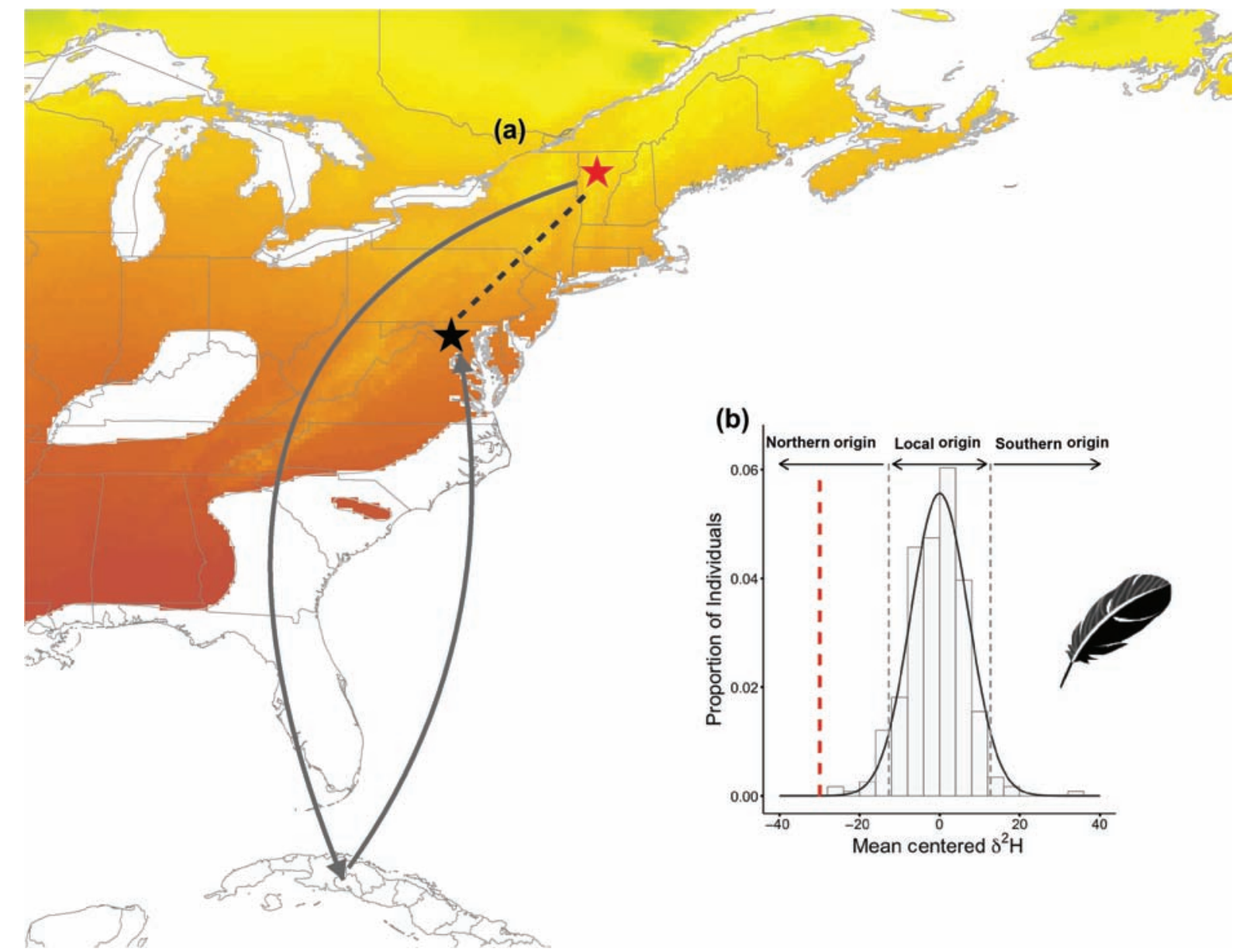

Figure 1. Conceptual diagram illustrating the use of stable hydrogen isotopes in the study of long-distance dispersal. The base map shows predicted deuterium abundance in bird feathers $\left(\delta^{2} \mathrm{H}_{f}\right)$ across the breeding range of American redstarts. (a) Redstarts grow feathers at their natal or breeding site (indicated by the red star) before migrating south to the Caribbean in the fall (indicated by the solid arrows). In the spring, individuals return to the breeding grounds and may breed at a site far from their previous location (indicated by the black star), resulting in long-distance dispersal (indicated by the dotted line). (b) For dispersing individuals, $\delta^{2} \mathrm{H}_{f}$ values will reflect the $\delta^{2} \mathrm{H}$ signature of their natal or previous breeding location, indicated by the dotted red line. This value can be compared to the local $\delta^{2} \mathrm{H}_{f}$ distribution to determine the probability that the individual originated locally. For example, the vertical dotted lines show the thresholds containing 90\% (9:1 odds) of the local distribution. Unknown-origin individuals with $\delta^{2} \mathrm{H}_{f}$ values within the threshold values are classified as local. Individuals with more negative $\delta^{2} \mathrm{H}_{f}$ values are classified as originating to the north (i.e. dispersing south) and individuals with more positive $\delta^{2} \mathrm{H}_{f}$ values were classified as originating to the south (i.e. dispersing north). The curve shown in the figure was empirically estimated from American redstarts known to have originated at the Patuxent Research Refuge between 2009-2012. The histogram shows the frequency of raw $\delta^{2} \mathrm{H}_{f}$ values from all unknown origin individuals captured in our population during those years. 
hydrogen values from these individuals did not differ from the values of recaptured adults (yearling mean $=-64.76 \%$, adult mean $=-64.72 \%, t=0.016, \mathrm{DF}=5, \mathrm{p}=0.988$ ). Therefore, we chose not to apply any age-correction to the hydrogen values from unbanded yearlings.

Given the low resolution of stable isotopes (Langin et al. 2007), the choice of odds ratios represents a trade-off between ensuring that local individuals are correctly classified as local (by using larger odds ratios) versus correctly classifying long-distance dispersers as immigrants (by using smaller odds ratios). To test the sensitivity of our results to the threshold used to classify dispersal status, we carried out the classifications using three progressively stringent thresholds (4:1 odds, 9:1 odds and 19:1 odds) and performed all analyses under each scenario. Because results were qualitatively similar across odds ratios, only results from the 4:1 odds ratio are presented in the text. Results based on the 9:1 and 19:1 odds ratios are presented in Supplementary material Appendix 3.

\section{Quantifying the drivers of long-distance dispersal}

To test our predictions about the drivers of long-distance dispersal in American redstarts, we focused on our analysis of the following predictors.

\section{1) Breeding-season phenology}

To quantify annual variation in the timing of phenology, we used the peak blossom date of cherry trees (Prunus $X$ yedoensis $)$ on the National Mall in Washington, DC $(\sim 30 \mathrm{~km}$ from our study site; <www.nps.gov/cherry/cherry-blossombloom.htm >). Because the accuracy of phenology estimates can be sensitive to differences in observers and monitoring procedures (Chung et al. 2011), the peak cherry blossom date, which is tracked annually by trained observers using a standardized procedure, provided a standard measure for comparing annual variation in the timing of phenology for our study site. The leafing phenology of most trees species, including cherry trees, and the emergence of spring-feeding caterpillars (the primary breeding resource for redstarts; Sherry and Holmes 1997) are strongly correlated with the average annual minimum temperature (Abu-Asab et al. 2001, Visser et al. 2006, Chung et al. 2011, Valtonen et al. 2011), so annual variation in cherry blossom phenology provided a reliable surrogate for the phenology of plants and insects in the region surrounding our study site. Peak cherry blossom dates for the years of our study were mean-centered on the long-term average so that positive values indicate later than average phenology and negative values indicate earlier than average phenology.

\section{2) Large-scale non-breeding habitat quality}

To quantify large-scale habitat quality experienced by redstarts during the non-breeding season, we used the mean normalized difference vegetation index (NDVI; $<$ http://pekko.geog.umd.edu/usda/test/ $>$ ) from January to March from the major islands in the Greater Antilles (Jamaica, Cuba, Cayman Islands, Haiti, Dominican Republic, and Puerto Rico). NDVI values provide an estimate of net primary productivity, which is highly correlated with food abundance and habitat quality for American redstarts during the non-breeding period (Studds and Marra 2007). Most redstarts breeding in the eastern United States winter in the Greater Antilles (Norris et al. 2006), so the values included in our analysis should reflect conditions experienced by most redstarts breeding at our study site. We chose to use NDVI values from January through March because this period has the largest impact on individuals transitioning into the breeding season (Studds and Marra 2007, Wilson et al. 2011). Annual NDVI values for the years of our study were mean-centered on the long-term average so that positive values indicate above-average habitat quality and negative values indicate below-average habitat quality.

\section{3) Non-breeding territory quality}

To test our prediction about the role of non-breeding territory quality, we used stable carbon isotope values from claw samples $\left(\delta^{13} \mathrm{C}\right)$. Stable-carbon isotope signatures of plants in the tropics vary by water availability (Michener and Lajtha 2008), which is positively correlated with the abundance of small, soft-bodied insects (Studds and Marra 2007). As a result, the amount of $\delta^{13} \mathrm{C}$ in tissues can be used as a proxy for habitat quality for insectivorous birds such as redstarts (Marra et al. 1998), with more negative values indicating wetter, higher quality habitat and more enriched values indicating drier, lower quality habitat. Turnover of $\delta^{13} \mathrm{C}$ in claws is on the order of weeks (Hahn et al. 2014), allowing us to use claw samples collected upon arrival on the breeding grounds to infer territory quality experienced during the preceding winter (Reudink et al. 2009). To aid in interpretability, we mean-centered $\delta^{13} \mathrm{C}$ so that positive values indicate higher than average habitat quality and negative values indicate lower than average quality.

A small number of individuals in our analysis $(n=6)$ were missing $\delta^{13} \mathrm{C}$ values due to errors that occurred while processing the samples in the mass spectrometer. Rather than removing these individuals from the analysis, and thereby reducing our ability to detect effects of the other predictors, missing $\delta^{13} \mathrm{C}$ values were assigned a value of 0 (indicating average non-breeding territory quality). A sensitivity analysis indicated that including these mean-values did not influence model selection results compared to dropping these individuals from the analysis.

\section{4) Age and sex}

For most songbirds, yearlings tend to disperse more often than adults and females tend to disperse more often than males (Greenwood and Harvey 1982, Paradis et al. 1998). Therefore, we also included by age class (yearling or adult) and sex in our analysis to control for influence of these individual-level traits.

\section{Statistical analysis}

We treated the three origin categories from our dispersal classification as an ordinal factor with levels defined by their spatial arrangement (south $<$ local $<$ north) and used a mixed effect cumulative logit regression (Christensen 2013a) to quantify the effects of the predictors outlined above. 
The full model included the following as fixed effects: age class (yearling or adult), sex, non-breeding territory quality $\left(\delta^{13} \mathrm{C}\right)$, breeding-season phenology (peak cherry blossom date), non-breeding habitat quality (NDVI), the interaction of the latter three with age class, and the interaction of breeding-season phenology with non-breeding territory quality. We also included year as a random effect to account for the non-independence of individuals sampled within the same year, though parameter estimates changed by $<1 \%$ when year was not included in the models. To test the significance of the fixed effects, we removed each predictor from the full model and then tested the fit of the reduced model using a likelihood ratio test. Interactions that were not significant were removed from the full model and only main effects were considered in the final analysis. For predictors that were included in significant interaction terms, main effects were tested by removing both the main effect and interaction. To test the sensitivity of our results to the threshold used to classify dispersal status, the analysis was repeated for classifications based on the 4:1, 9:1, and 19:1 odds ratios. We interpreted consistency in the significance, sign, and magnitude of predictors across the odds ratios as strong evidence that a factor influences long-distance dispersal. All models were fit in R (ver. 3.0.2; R Core Team) using the clmm2 function in the package ordinal (ver. 2013.9-30; Christensen 2013a).

The cumulative logit model assumes that the effects of predictor variables are equal across all categories of the response variable, known as the proportional odds (PO) assumption (Guisan and Harrell 2000). To test that our data conformed to the $\mathrm{PO}$ assumption, we relaxed the $\mathrm{PO}$ assumption for each fixed effect predictor in the full models and used likelihood ratio tests to determine whether this nominal model improved the fit compared to the fully ordinal model (Christensen 2013b). For our data, the nominal models did not fit significantly better than PO models, indicating the $\mathrm{PO}$ assumption was not violated for any predictor.

\section{Results}

Over the course of our study, we sampled a total of 320 redstarts and our data indicate that long-distance dispersal is relatively rare in this species, with the majority of individuals $(85.6 \%)$ in both age and sex classes having $\delta^{2} \mathrm{H}_{f}$ values consistent with a local origin (Supplementary material Appendix 2, Table A1). In addition, our data indicated that although the majority (69\%) of immigrants in our population originated to the north of our study site, the source of immigrants showed significant annual variation over the course of the study (Fig. 2; Supplementary material Appendix 3, Fig. A1). From 2009-2011, the majority of immigrants into our population $(78.4 \%)$ originated from north of our study site (Fig. 2; Supplementary material Appendix 2, Table A1). In 2012, however, the majority of immigrants (70\%) originated from south of our study site (Fig. 2; Supplementary material Appendix 3, Table A1).

Both the peak cherry blossom date and late-season NDVI in the Greater Antilles showed substantial variation over the course of our study (Fig. 2), providing a unique opportunity to test how these factors influence long-distance dispersal

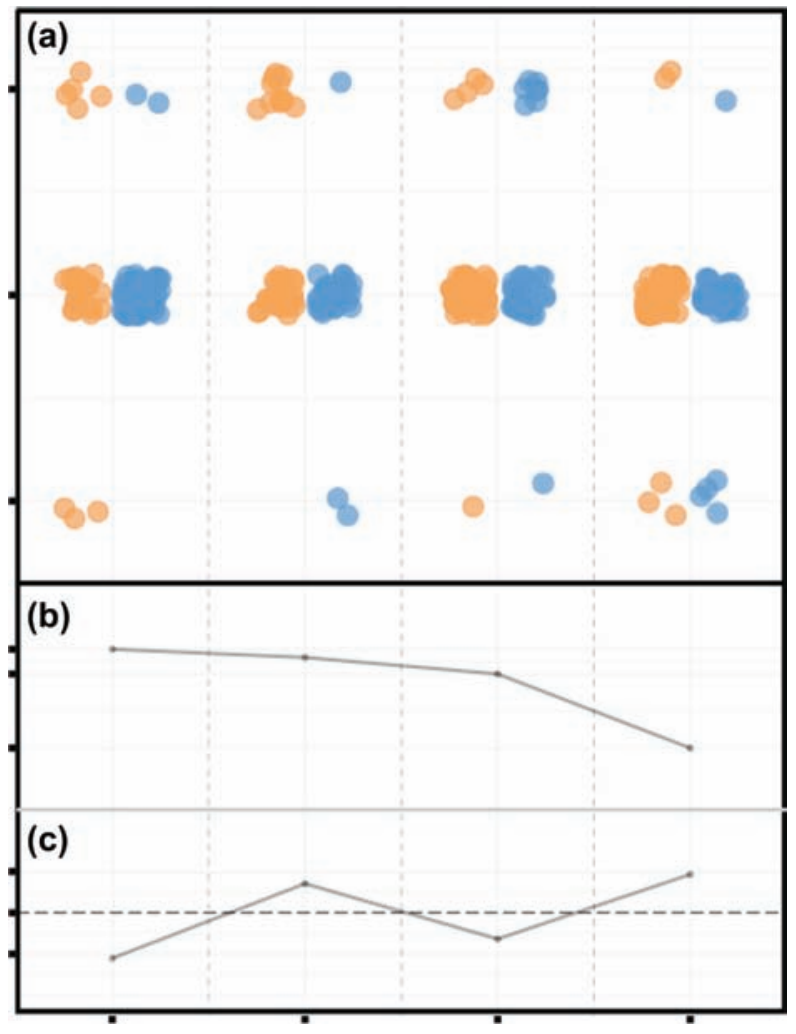

Figure 2. (a) Patterns of immigration in the study population from 2009 to 2012. Each point represents one individual and its predicted origin based on $\delta^{2} \mathrm{H}_{f}$ values using a 4:1 odds ratio (see text). Adults are shown in blue and yearlings are shown in orange. (b) The peak cherry blossom date on the National Mall from 2009 to 2012. (c) NDVI values from January to March in the Greater Antilles. NDVI values are mean-centered so that positive values (above the dotted line) represent above average primary productivity and negative values (below the dotted line) represent below average primary productivity.

in redstarts. Consistent with the phenology hypothesis, the onset of breeding-season phenology was the most consistent factor influencing dispersal status in our models, with the main effect of the peak cherry blossom date significant in all models regardless of the odds ratio used to classify dispersal status (Table 1, Supplementary material Appendix 3, Table $\mathrm{A} 2$ and $\mathrm{A} 3$ ). As predicted, the coefficients were positive in all models, indicating that the odds of originating from the south increase in years with early phenology (Fig. 3). Furthermore, the interaction of peak cherry blossom date and age class was not significant in any of the models, indicating that both long-distance natal and breeding dispersal were sensitive to the influence of breeding-season phenology.

Our results also provide evidence that large-scale non-breeding habitat quality influenced long-distance dispersal, although the results were less consistent across odds ratios. When dispersal status was classified using the 4:1 odds ratio, the interaction of NDVI with age class was significant (Table 1), indicating that long-distance natal dispersal was influenced by habitat quality experienced during the preceding winter. As predicted, the coefficient for the interaction terms were positive, indicating that yearlings were more likely to disperse north following winters with poor habitat quality in the Caribbean (Fig. 4). In contrast, 
Table 1. Factors influencing long-distance dispersal in yearling and adult age classes of American redstarts. Parameter estimates $(+/-$ one standard error) are based on a mixed-effect cumulative logit regression with dispersal status classified using a 4:1 odds ratio and year included as a random effect. For each parameter, $\chi^{2}, \mathrm{DF}$, and $p$ values are based on a likelihood ratio test (LRT) comparing the model without that parameter to the full model. Parameters significant at the $\alpha=0.05$ level are indicated in bold. LRT results for the main effect of non-breeding habitat quality were estimated by removing both the main effect and interaction from the full model. The interactions of breeding-season phenology and non-breeding territory quality with age class were not significant and are not presented in the table.

\begin{tabular}{|c|c|c|c|c|c|}
\hline Variable & Estimate \pm SE & $z$ & $\chi^{2}$ & DF & $\mathrm{p}$ \\
\hline Age class & $0.673 \pm 0.35$ & 1.935 & 6.51 & 2 & 0.039 \\
\hline Sex & $-0.031 \pm 0.37$ & -0.084 & 0.007 & 1 & 0.933 \\
\hline Non-breeding territory quality $\left(\delta^{13} C\right)$ & $-0.191 \pm 0.29$ & -0.648 & 0.41 & 1 & 0.521 \\
\hline Breeding-season phenology & $0.141 \pm 0.05$ & 3.091 & 5.05 & 1 & 0.025 \\
\hline Non-breeding habitat quality (adults) & $-0.045 \pm 2.17$ & -0.021 & $<0.001$ & 1 & 0.988 \\
\hline Non-breeding habitat quality (yearlings) & $6.35 \pm 2.99$ & 2.119 & 4.66 & 1 & 0.031 \\
\hline
\end{tabular}

the effect of NDVI on adults was not significant (Table 1), indicating that long-distance breeding dispersal was not sensitive to non-breeding habitat quality. When dispersal status was classified using the 9:1 odds ratio, the interaction of NDVI with age class was not significant but the main effect was significant at the $\alpha=0.1$ level (Supplementary material Appendix 3, Table A2). Consistent with the results of the 4:1 model, the coefficient for NDVI was positive, indicating that individuals were more likely to disperse north following winter with poor non-breeding habitat quality (Supplementary material Appendix 3, Fig. A3). In contrast, neither the main effect of NDVI nor the interaction of NDVI with age class were significant when dispersal status was classified using the conservative 19:1 odds ratio (Supplementary material Appendix 3, Table A3). For both the 9:1 and 19:1 odds ratios, the large error associated with the coefficients suggest that we did not have the statistical power to detect significance under these restrictive thresholds, especially for interaction terms. Nonetheless, the significant results under the 4:1 odds ratio and the consistency of the positive coefficients across the three odds ratios suggest that non-breeding conditions have a strong impact on long-distance dispersal in both age classes in this species.

Contrary to the prediction of the saturation hypothesis, non-breeding territory quality $\left(\delta^{13} \mathrm{C}\right)$ was not significant under any of the three odds ratios (Table 1 , Supplementary material Appendix 3, Table A2 and A3), indicating that neither natal dispersal nor breeding dispersal was influenced by quality of an individual's territory during the preceding winter. Furthermore, there was no evidence that the effect of non-breeding territory quality was influenced by breeding-season phenology (Table 1, Supplementary material Appendix 3, Table A2 and A3).

Of the other individual-level traits that we included in our models, only age class was found to be significant when dispersal status was classified using the $4: 1$ odds ratio (Table 1). Over the four years of our study, the immigration rate was higher for yearlings $(18.1 \%)$ than for adults (11.2\%; Supplementary material Appendix 2, Table A1), suggesting that long-distance natal dispersal is more common than long-distance breeding dispersal in this species. However, the immigration rates for each age class showed substantial variation among years and in both 2011 and 2012, our population received more adult immigrants than yearlings (Fig. 2; Supplementary material Appendix 2 , Table A1), indicating that long-distance breeding dispersal may occur at similar rates to long-distance natal dispersal in some years. Across all years, immigration rates were generally lower for females $(11.02 \%)$ than for males $(14.68 \%)$ but sex was not significant under any odds ratio (Table 1, Supplementary material Appendix 3, Table A2 and $\mathrm{A} 3$ ).

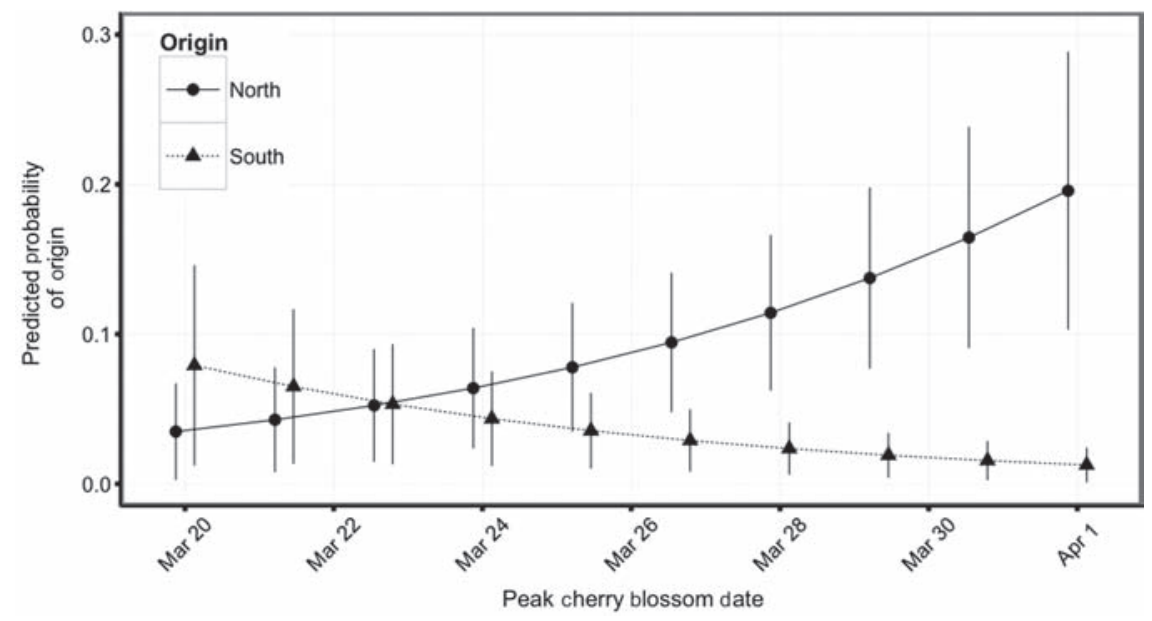

Figure 3. Predicted probability of origin as a function of cherry blossom phenology on the breeding grounds based on the full model using the $4: 1$ odds ratio to classify dispersal status and including year as a random effect. Triangles and dashed lines show the probability of originating to the south; circles and solid lines show the probability of originating to the north. Vertical bars show $95 \%$ CI. 


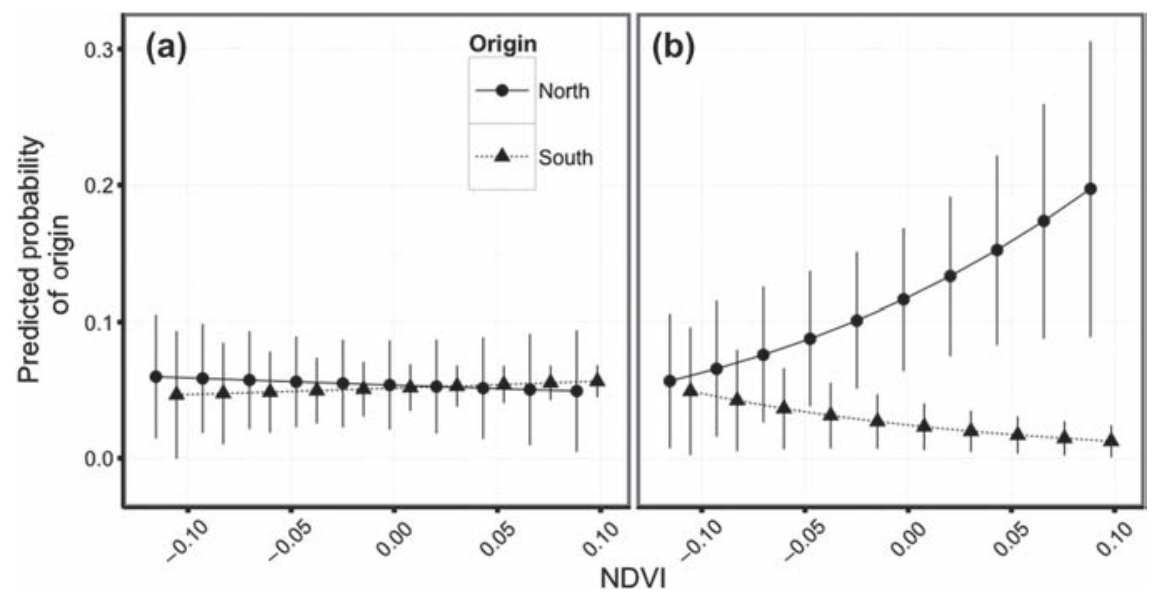

Figure 4. Predicted probability of origin for (a) adults and (b) yearlings as a function of the normalized difference vegetation index (NDVI) values from January to March in the Greater Antilles based on the full model using the 4:1 odds ratio to classify dispersal status and including year as a random effect. NDVI values were mean-centered on the long-term average, thus positive values indicate higher quality conditions and negative values indicate lower quality conditions. Triangles and dashed lines show the probability of originating to the south; circles and solid lines show the probability of originating to the north. Vertical bars show $95 \%$ CI.

\section{Discussion}

In this study, we used a spatially-unbiased intrinsic marker to uncover large-scale annual variation in the source of immigrants in our study population of American redstarts. From 2009-2011, 80\% of the immigrants in our population had $\delta^{2} \mathrm{H}_{f}$ values consistent with an origin north of our study site. This bias is consistent with geographic variation in the relative breeding abundance of redstarts, which is approximately four times higher in the regions to the north of our study site than in the regions to the south (Norris et al. 2006). This result suggests that, for American redstarts, long-term patterns of long-distance dispersal may be driven primarily by the number of potential dispersers in a given region (Graves 1997). However, in 2012 we observed the opposite pattern, with virtually all immigrants originating to the south, indicating that breeding density was not the sole driver of immigration into our population. The sharp distinction between years and the consistency across age and sex classes suggest that these patterns were not due to aberrant $\delta^{2} \mathrm{H}_{f}$ values, such as local individuals with abnormally enriched or depleted $\delta^{2} \mathrm{H}_{f}$ values (Langin et al. 2007) or to individuals molting their feathers at southern latitudes during migration (Reudink et al. 2008).

Instead, our data provide evidence that in certain years, large-scale environmental conditions resulted in a significant influx of southern immigrants and a corresponding decrease in northern immigrants, consistent with the predictions of the phenology hypothesis. In 2012, the peak cherry blossom date occurred approximately two weeks earlier than normal, resulting in a striking influx of southern immigrants in our population and virtually no northern immigrants (Fig. 2; Supplementary material Appendix 3, Fig. A1). Under these conditions, individuals from southern latitudes likely arrived at their natal or previous breeding location after food resources had peaked and chose to continue migrating northward to locate breeding sites with optimal resource levels.

Although the sensitivity of adults to phenological cues is surprising given the high rates of site fidelity observed in most adult songbirds (Greenwood and Harvey 1982), other studies of migratory birds have also found that breeding dispersal can be influenced by climate conditions (Møller et al. 2006, Figuerola 2007). Thus, although long-distance breeding dispersal is generally rare in most birds (Paradis et al. 1998), our results indicate that dispersal behavior of experienced breeders may be more flexible than is commonly believed. If true, breeding dispersal may play an underappreciated role in shaping population dynamics, gene flow, and responses to climate change in many species.

Our results also support the prediction that non-breeding habitat conditions influence the direction of long-distance natal dispersal in American redstarts. In 2009, but not 2010 or 2011, nearly half of the yearling immigrants in our population originated to the south (Fig. 2), despite relatively late breeding-season phenology. Habitat quality was far below average across the Caribbean in the winter preceding the 2009 breeding season (Fig. 2), conditions which are known to delay departure on spring migration for redstarts (Marra et al. 1998). If some individuals use the onset of breedingseason phenology as a cue to select breeding sites (Studds et al. 2008, Husek et al. 2014), later-migrating yearlings that would normally have bred in the southern portion of the range may have chosen to migrate further north to locate suitable breeding sites (Studds et al. 2008). In contrast, immigration of southern yearlings was low or absent in 2010 and 2011, years with average breeding-season phenology and near average non-breeding conditions (Fig. 2). These results corroborate the earlier findings of Studds et al. (2008) and provide further evidence that carry-over effects from the non-breeding season are an important driver of natal dispersal in this species.

Although the patterns we observed were driven by a small number of long-distance immigrants (47/320 individuals), the observed frequency of long-distance dispersal was consistent with the relative rarity of long-distance dispersal reported in other songbirds (Paradis et al. 1998). Because many ecological and evolutionary processes are sensitive to rare long-distance dispersal events (Kot et al. 1996, Higgins 
and Richardson 1999, Clark et al. 2001), these few individuals can have a disproportionate influence on population-level processes. As our results demonstrate, the ability to empirically quantify the drivers of these rare long-distance events can provide novel insights into this fundamental process. Furthermore, direct evidence linking climate conditions to long-distance dispersal behavior is rare (Møller et al. 2006, Massot et al. 2008, Husek et al. 2014) and our results have important implications for predicting how migratory species will respond to climate change.

As breeding-season phenology in temperate areas has advanced in recent decades, there is evidence that some migratory species have not advanced their arrival dates on the breeding grounds to keep pace (Both and Visser 2001). As a result, in years with early breeding-season phenology, the resources necessary for reproduction peak before individuals initiate reproductive activities (Both et al. 2006) and this phenological mismatch has been linked to reduced reproductive success in several long-distance migratory bird species (Both et al. 2006, Saino et al. 2011). As temperate areas continue to warm, there is concern that the magnitude of phenological mismatches will increase, possibly resulting in declines and extinction of many migratory bird species (Møller et al. 2008).

At present, most research on the response of migratory birds to climate change has focused on the ability of individuals to adjust the speed of migration in response to environmental conditions experienced en route (Marra et al. 2005, Hurlbert and Lian 2012) or on the evolutionary potential of populations to adjust the timing of migration or breeding over longer time scales (Charmantier and Gienapp 2014). In contrast, research on the ability of individuals to respond to advancing phenology via long-distance dispersal has largely been neglected. Nonetheless, evidence that migratory birds use phenological cues to select breeding sites is beginning to emerge. For example, Husek et al. (2014) recently demonstrated that pied flycatchers Ficedula hypoleuca were more likely to disperse north in years with warm spring temperatures and early food resource phenology but more likely to return to their natal area in years with average temperatures and food resource phenology. Though the dispersal events recorded by Husek et al. (2014) were restricted to a $10-\mathrm{km}$ latitudinal gradient, our results and those of Studds et al. (2008) indicate that similar behaviors occur in American redstarts over regional spatial scales.

However, whether long-distance dispersal buffers individuals against the negative consequences of early phenology requires further research, especially in light of the fact that both phenological mismatches and dispersal in response to phenology have been observed in different populations of the same species (Both et al. 2006, Husek et al. 2014). Dispersal is a complex behavioral process that is influenced by a large number of evolutionary and ecological forces (Clobert et al. 2012), many of which are poorly understood (Ronce 2007). Further research is needed to understand if and under what circumstances long-distance dispersal represents a viable strategy for coping with annual variation in the timing of resource phenology.

Even if long-distance dispersal buffers individuals against the impacts of advancing phenology of breeding resources, our results indicate that the ability of migratory individuals to respond to breeding-season phenology may be constrained by conditions experienced during the non-breeding period. Climate models predict that the Caribbean basin will receive significantly less precipitation in the coming century (Neelin et al. 2006), which will result in overall poorer habitat quality for American redstarts and many other insectivorous songbirds that winter in the Caribbean. Drier conditions will result in lower food resources, which in turn will delay departure on spring migration and force individuals to disperse farther north to synchronize reproductive efforts with optimal breeding conditions. Unfortunately, advancing breeding-season phenology on temperate breeding grounds may confound these effects, although the interacting effects of temperate and tropical climate change on migratory species remains largely unstudied (Small-Lorenz et al. 2013). As our results underscore, developing a mechanistic understanding of long-distance dispersal and understanding how individual organisms respond to shifting environmental conditions requires moving beyond the breeding-season paradigm that has dominated both dispersal and climate change research and towards a perspective that considers the role of events experienced throughout their entire annual cycle.

Acknowledgements - Funding for fieldwork was provided by the COSMOS Foundation, the American Ornithologists Union, the Washington Biologists Field Club, the Maryland Ornithological Society and the National Science Foundation. CSR was supported by the BEES/BISI program, a Wiley Dissertation Fellowship from the Univ. of Maryland, and a Pre-doctoral fellowship from the Smithsonian Inst.

\section{References}

Abu-Asab, M. S. et al. 2001. Earlier plant flowering in spring as a response to global warming in the Washington, DC area. - Biodivers. Conserv. 10: 597-612.

Baguette, M. 2003. Long distance dispersal and landscape occupancy in a metapopulation of the cranberry fritillary butterfly. - Ecography 26: 153-160.

Bohrer, G. et al. 2005. Effects of long-distance dispersal for metapopulation survival and genetic structure at ecological time and spatial scales. - J. Ecol. 93: 1029-1040.

Both, C. and Visser, M. E. 2001. Adjustment to climate change is constrained by arrival date in a long-distance migrant bird. - Nature 411: 296-298.

Both, C. et al. 2006. Climate change and population declines in a long-distance migratory bird. - Nature 441: 81-83.

Charmantier, A. and Gienapp, P. 2014. Climate change and timing of avian breeding and migration: evolutionary versus plastic changes. - Evol. Appl. 7: 15-28.

Christensen, R. H. B. 2013a. Ordinal: regression models for ordinal data. - R package ver. 2013.9-30, <www.cran.r-project. org/package $=$ ordinal $/>$.

Christensen, R. H. B. 2013b. A tutorial on fitting cumulative link models with the ordinal package. $-<$ http://cran.r-project.org/ web/packages/ordinal/vignettes/clm_tutorial.pdf $>$.

Chung, U. et al. 2011. Predicting the timing of cherry blossoms in Washington, DC and Mid-Atlantic States in response to climate change. - PLoS One 6: e27439.

Clark, J. S. et al. 2001. Invasion by extremes: population spread with variation in dispersal and reproduction. - Am. Nat. 157: 537-554. 
Clobert, J. et al. 2012. Dispersal ecology and evolution. - Oxford Univ. Press.

Figuerola, J. 2007. Climate and dispersal: black-winged stilts disperse further in dry springs. - PLoS One 2: e539.

Graves, G. R. 1997. Geographic clines of age ratios of blackthroated blue warblers (Dendroica caerulescens). - Ecology 78 : 2524-2531.

Green, A. J. and Figuerola, J. 2005. Recent advances in the study of long-distance dispersal of aquatic invertebrates via birds. - Divers. Distrib. 11: 149-156.

Greenwood, P. J. and Harvey, P. H. 1982. The natal and breeding dispersal of birds. - Annu. Rev. Ecol. Evol. Syst. 12: 1-21.

Guisan, A. and Harrell, F. E. 2000. Ordinal response regression models in ecology. - J. Veg. Sci. 11: 617-626.

Haché, S. et al. 2012. Assigning birds to geographic origin using feather hydrogen isotope ratios $\left(\delta^{2} \mathrm{H}\right)$ : importance of year, age, and habitat. - Can. J. Zool. 90: 722-728.

Hahn, S. et al. 2014. Avian claw morphometry and growth determine the temporal pattern of archived stable isotopes. - J. Avian Biol. 45: 202-207.

Harrison, X. A. et al. 2011. Carry-over effects as drivers of fitness differences in animals. - J. Anim. Ecol. 80: 4-18.

Higgins, S. I. and Richardson, D. M. 1999. Predicting plant migration rates in a changing world: the role of long-distance dispersal. - Am. Nat. 153: 464-475.

Hobson, K. A. et al. 2012. Linking hydrogen $\left(\delta^{2} \mathrm{H}\right)$ isotopes in feathers and precipitation: sources of variance and consequences for assignment to isoscapes. - PLoS One 7: e35137.

Hurlbert, A. H. and Lian, Z. 2012. Spatiotemporal variation in avian migration phenology: citizen science reveals effects of climate change. - PLoS One 7: e31662.

Husek, J. et al. 2014. Natal dispersal based on past and present environmental phenology in the pied flycatcher (Ficedula bypoleuca). - Oecologia 174: 1139-1149.

Kot, M. et al. 1996. Dispersal data and the spread of invading organisms. - Ecology 77: 2027-2042.

Langin, K. M. et al. 2007. Hydrogen isotopic variation in migratory bird tissues of known origin: implications for geographic assignment. - Oecologia 152: 449-457.

Lemon, R. E. et al. 1996. Breeding dispersions and site fidelity of American redstarts (Setophaga ruticilla). - Can. J. Zool. 74: 2238-2247.

Marra, P. P. et al. 1998. Linking winter and summer events in a migratory bird by using stable-carbon isotopes. - Science 282 : 1884-1886.

Marra, P. P. et al. 2005. The influence of climate on the timing and rate of spring bird migration. - Oecologia 142: 307-315.

Massot, M. et al. 2008. Climate warming, dispersal inhibition and extinction risk. - Global Change Biol. 14: 461-469.

McKellar, A. E. et al. 2013. Winter rainfall predicts phenology in widely separated populations of a migrant songbird. - Oecologia 172: 595-605.

Michener, R. and Lajtha, K. 2008. Stable isotopes in ecology and environmental science. - Blackwell.

Møller, A. P. et al. 2006. Dispersal and climate change: a case study of the Arctic tern Sterna paradisaea. - Global Change Biol. 12: 2005-2013.

Møller, A. P. et al. 2008. Populations of migratory bird species that did not show a phenological response to climate change are declining. - Proc. Natl Acad. Sci. USA 105: 16195-16200.
Nathan, R. et al. 2003. Methods for estimating long-distance dispersal. - Oikos 103: 261-273.

Neelin, J. et al. 2006. Tropical drying trends in global warming models and observations. - Proc. Natl Acad. Sci. USA 103: 6110-6115.

Norris, D. R. et al. 2006. Migratory connectivity of a widely distributed songbird, the American redstart (Setophaga ruticilla). - Ornithol. Monogr. 61: 14-28.

Paradis, E. et al. 1998. Patterns of natal and breeding dispersal in birds. - J. Anim. Ecol. 67: 518-536.

Pyle, P. et al. 1997. Identification guide to North American birds: a compendium of information on identifying, ageing, and sexing waterbirds, diurnal raptors, and Gallinaceous birds in the hand. Anatidae to Alcidae. - Slate Creek Press.

Reudink, M. W. et al. 2008. Molt-migration in the American redstart (Setophaga ruticilla) revisited: explaining variation in feather $\delta \mathrm{D}$ signatures. - Auk 125: 744-748.

Reudink, M. W. et al. 2009. Non-breeding season events influence sexual selection in a long-distance migratory bird. - Proc. R. Soc. B 276: 1619-1626.

Ronce, O. 2007. How does it feel to be like a rolling stone? Ten questions about dispersal evolution. - Annu. Rev. Ecol. Evol. Syst. 38: 231-253.

Saino, N. et al. 2011. Climate warming, ecological mismatch at arrival and population decline in migratory birds. - Proc. R. Soc. B 278: 835-842.

Savolainen, O. et al. 2007. Gene flow and local adaptation in trees. - Annu. Rev. Ecol. Evol. Syst. 38: 595-619.

Sherry, T. W. and Holmes, R. T. 1997. American redstart (Setophaga ruticilla). - In: Poole, A. (ed.), The birds of North America online. Cornell Lab of Ornithology, Ithaca, NY.

Small-Lorenz, S. L. et al. 2013. A blind spot in climate change vulnerability assessments. - Nat. Clim. Change 3: 91-93.

Studds, C. E. and Marra, P. P. 2007. Linking fluctuations in rainfall to nonbreeding season performance in a long-distance migratory bird, Setophaga ruticilla. - Clim. Res. 35: $115-122$.

Studds, C. E. et al. 2008. Natal dispersal driven by environmental conditions interacting across the annual cycle of a migratory songbird. - Proc. Natl Acad. Sci. USA 105: 2929-2933.

Studds, C. E. et al. 2012. Stable-hydrogen isotope measures of natal dispersal reflect observed population declines in a threatened migratory songbird. - Divers. Distrib. 18: 919-930.

Valtonen, A. et al. 2011. Environmental controls on the phenology of moths: predicting plasticity and constraint under climate change. - Oecologia 165: 237-248.

van Wilgenburg, S. L. et al. 2012. Assessing dispersal in threatened migratory birds using stable hydrogen isotope $(\delta \mathrm{D})$ analysis of feathers. - Endanger. Species Res. 16: 17-29.

Visser, M. E. et al. 2006. Shifts in caterpillar biomass phenology due to climate change and its impact on the breeding biology of an insectivorous bird. - Oecologia 147: 164-172.

Wilson, S. et al. 2011. Range-wide effects of breeding- and nonbreeding-season climate on the abundance of a Neotropical migrant songbird. - Ecology 92: 1789-1798.

Winkler, D. 2005. How do migration and dispersal interact? - In: Greenberg, R. and Marra, P. (eds), Birds of two worlds: the ecology and evolution of migration. John Hopkins Univ. Press, pp. 401-413. 